\title{
Türk yapı sektöründe yapı bilgi modellemesinin adaptasyonu
}

\author{
Merve ERDİK ${ }^{1}$, Yeliz TÜLÜBAŞ GÖKUÇ ${ }^{2, * *}$ \\ ${ }^{1}$ Balıkesir Üniversitesi Fen Bilimleri Enstitüsü, Çă̆lş kampüsü, Balıkesir \\ ${ }^{2}$ Balıkesir Üniversitesi, Mimarlık Fakültesi, Mimarlık Bölümü̈, Çağıs kampüsü, Balıkesir
}

Geliş Tarihi (Received Date): 28.03.2019

Kabul Tarihi (Accepted Date): 11.09.2019

\section{Öz}

Teknolojinin son dönemde en önemli inovasyonu olan BIM'in (Yapı Bilgi Modellemesi) Türk yapı sektöründe adaptasyonunu incelemeyi amaçlayan bu çalışma için gerekli olan bilgiler yapılan literatür taraması sonucu elde edilen veriler doğrultusunda oluşturulan anket çalışması yapılarak toplanmıştır. Tasarım ve inşaat firmalarından oluşan anket katılımcılarının çoğu sektördeki paydaşların ve alt yüklenicilerin teknik olarak yetersiz olmasını BIM kullanımının önündeki en büyük engel olarak belirtmişlerdir. Ayrica BIM'in potansiyel faydalarının firmalar tarafindan henüz anlaşılamamış olması ve BIM konusunda uzman iş gücü eksikliği BIM adaptasyonunu engelleyen en önemli faktörler olarak ortaya çıkmıştır. Firmaları BIM kullanımına yöneltecek faktörlerin en önemlileri ise; tasarım çözümlerinin daha iyi görselleştirilmesi, tasarım önerilerinin daha iyi anlaşılması ve titizlikle analiz edilmesi ve simülasyonların daha kolay oluşturulmasıdır. Yapı bilgi modellemesi kavramının önemi zamanla anlaşılmakta olup kullanımı artmaya başlamıştır. İlk olarak, havalimant, rayl sistem ve hastane projelerinde kullanilan BIM'in klsa zamanda Türkiye'de yapı sektörünün vazgeçilmez bir parçası olacağı düşülmektedir. Projelerde BIM kullanımının zorunlu hale getirilmesi ve BIM'in adaptasyon sürecini engelleyen faktörlerin minimuma indirilmesi, mümkünse ortadan kaldırılması amaçlanmalıdır.

Anahtar kelimeler: Yapı bilgi modellemesi, BIM, yapı sektörü, yapımda inovasyon.

\footnotetext{
Merve ERDIK, merveerdik92@ @otmail.com, https://orcid.org/0000-0002-5017-4223

*Yeliz TÜLÜBAŞ GÖKUÇ, yeliztulubas@ hotmail.com, https://orcid.org/ 0000-0003-3594-7977

Bu çalışma; 1. yazarın Balıkesir Üniversitesi Fen Bilimleri Enstitüsü Mimarlık Anabilim dalı yüksek lisans programında hazırladığı 'Yapı sektöründe yapı bilgi modellemesinin adaptasyonu”' başlıklı tezden üretilmiştir.
} 


\title{
Adoption of building information modeling in the Turkish
}

\author{
construction sector
}

\begin{abstract}
The purpose of this research is to determine the factors that contribute to adoption of the Building Information Modeling in the construction sector. The necessary information for this study which aims to examine the adoption of BIM (Building Information Modeling), which is the most important innovation of technology, in Turkish construction sector was collected by a questionnaire study based on the data obtained from the literature review. Most of the survey participants stated that technical insufficiency of the stakeholders and subcontractors was the most important factor for BIM adoption in the sector. In addition, the potential benefits of BIM have not yet been understood by the companies and the lack of skilled workforce is the most important factor that preventing the BIM adoption. The most important factors that lead firms to use of BIM are the better visualization of design solutions, better understanding of design proposals and more accurate analysis of simulations. The importance of building information modeling is increasing over time and use of BIM has become widespread in. BIM was primarily used in rail system projects, airports and hospital projects. It is assumed that BIM will be an indispensable part of the construction sector in a short time. For this reason, use of BIM in the projects should be made compulsory. The factors that hinder the adoption process of BIM should be minimized or even eliminated.
\end{abstract}

Key words: Building information modeling, BIM, construction sector, construction innovation.

\section{Giriş}

Yap1 sektörü; bilgi yoğun bir sektördür. Bir yapının planlama, tasarım, yapım ve işletilmesini de kapsayan yaşam döngüsü boyunca, çok miktarda bilgi kullanımı söz konusudur. İnşaat projeleri karmaşık yapıdadır ve gün geçtikçe yönetimi daha da zorlaşmaktadır. Yapı Bilgi Modellemesi (Building Information Modeling-BIM); farklı disiplinler arasında iş birliğine ve birlikte çalışabilirliğe katkı sağlayan yap1 sektöründeki en önemli teknolojik yeniliklerden birisidir. BIM gibi, teknolojideki yeni gelişmeler inşaat ve tasarım firmaları üzerinde ciddi rekabet baskısı yaratır. Tasarım ve inşaat firmaları bu rekabet ortamında hayatta kalabilmek ve gelişmek için yenilikçi yeteneklerini geliştirmek ve yeni teknolojileri adapte etmek ihtiyacı hissederler. Bir inşaat projesini sanal ortamda simüle eden ve projenin başlangıcından yıkımına kadar her aşamasında kullanılabilen BIM; tüm yapı yaşam döngüsü boyunca önemli avantajlar sağlamaktadır [1]. Elde edilen bu faydalara rağmen, BIM'in yap1 sektöründe adaptasyonu profesyonellerin BIM'i benimseme konusundaki dirençleri dolayısıyla ve bu çalışmada da açıklanan bazı faktörler nedeniyle hala sınırlıdır. Sonuç olarak BIM'in adaptasyonu beklenenden yavaş olmuştur [2]. Yapı sektöründe faaliyet gösteren tasarım ve inşaat firmaları BIM kullanımına engel teşkil eden birçok faktörle karşılaşmaktadır. $\mathrm{Bu}$ da BIM kullanımının adaptasyon sürecine etki etmektedir. Çalışma, BIM'in Türk yapı sektörüne adapte edilmesine katkıda bulunabilecek ve kullanımına engel oluşturan faktörleri belirlemeyi amaçlamaktadır. 


\section{Yapı Bilgi Modellemesi (Building Information Modeling-BIM)}

Yap1 sektöründe son yıllarda meydana gelen teknolojik gelişmelerle birlikte yap1 firmaları arasındaki rekabet ortamı giderek artmaktadır. BIM bu bağlamda önemi giderek artan ve gelecek vaat eden önemli gelişmelerden biridir. Günümüzde büyük alanlı, farklı teknolojiler içeren ve karmaşık işlevli yapıların tasarlanmasında, çeşitli disiplinlerden uzman kişilerin bilgi girişine gereksinim duyulmaktadır. Mimari ve mühendislik tasarım sürecinin dijital ortamlarda yapılmaya başlanmasından dolayı, mimar ve çeşitli disiplinlerdeki mühendislerin bilgi alışveriş şekli de değişikliğe uğramıştır [3].

BIM, mimarlar, mühendisler, işverenler ve yükleniciler arasında üç boyutlu bir ortamda iş birliğine dayalı disiplinler arası bir bilgi paylaşımı sağlayarak yapının ilk tasarım sürecinden başlayan yapım aşaması ve yapının kullanım aşamasına kadar uzanan bir bilgi yönetim sistemidir. BIM çok çeşitli projelerde kullanılabilmektedir. Yap1 yönetimi, tesis yönetimi, maliyet yönetimi ve proje yönetimi gibi süreçleri desteklemektedir. BIM, yapı yaşam döngüsü boyunca ihtiyacı olan tüm veriyi sayısal bir veri tabanında depolayan ve proje tasarımına yön veren bir metottur. Tekrar gözden geçirme yine bu digital veri tabanında yapıldığı için, dokümanlarda yapılmış olan herhangi bir değişiklik, veri tabanında tüm dokümanlarda görünür. Dolayısıyla BIM yalnızca tasarımcının değil, tüm proje paydaşlarının ortak olarak kullanabileceği bir bilgi deposu oluşturur [4].

\subsection{Dünyada ve Türk yapı sektöründe BIM kullanımı}

BIM kullanımına duyulan ilgi, pek çok ülkede giderek artmaya başlamıştır. BIM kullanımı bazı ülkelerde devlet teşviki ve zorunluluğunun katkısı ile yaygınlaşmıştır. Pek çok Avrupa ülkesi BIM konusunda standartlar geliştirmiştir. ABD, yapı sektöründe BIM'in uygulanmasında lider ülkelerden biridir ve BIM konusunda kendi standartlarını geliştirmiştir [5]. McGraw-Hill'in 2012 yılında yaptığı bir araştırmaya göre, Kuzey Amerika'da 2007 yılında yapı sektörünün \%28'i BIM araçlarını kullanmakta iken bu oran 2012 yılında \%71'e yükselmiştir [6,7].

2016 y1lından itibaren İngiltere hükümeti kamu sektöründeki projelerde BIM kullanımını zorunlu hale getirerek Avrupa'daki ülkeler arasında BIM lideri olmayı hedeflemektedir. Batı Avrupa'da ise, BIM kabul oranı \%36'dır[8]. Birçok Avrupa ülkesinde örneğin; Almanya, Fransa, Brezilya, Avusturya, Finlandiya, Danimarka, Norveç ve İsveç'de BIM konusunda geniş bir sektör bilinci edinilmesi ve benimsenmesi yönünde çalışmalar yapılmaktadır. Norveç’te BIM uygulamalarına devlet tesislerinin yapımından yönetiminden ve geliştirilmesinden sorumlu bir firma olan Statsbygg öncülük etmektedir ve 2010 yllından itibaren BIM zorunlu hale getirilmiştir [9]. Danimarka güçlü bir BIM destekleyicisidir ve BIM'e yönelik araştırma ve geliştirme faaliyetlerine yoğun bir yatırım yapmaktadır. Bazı devlet kurumları projelerde BIM kullanımını zorunlu kılmaktadır [9]. Güney Asya'da ülkelerinden Hong Kong'da BIM uygulaması tasarımları bütünleştirmesi, değişikliklere olanak vermesi, üretkenliği üst düzeye çıkararak hataları tespit etmesi ve ortadan kaldırması sebebiyle hızla ilerlemektedir [10]. 2014 yılından itibaren hükümet tüm kamu konut projelerinde BIM kullanımını desteklemektedir [11]. Çin'de, hükümet BIM çerçevesini formüle etmek için beş yıllık bir plan (2011-2015) oluşturmuştur. Afrika'da BIM uygulaması ülkelere göre değişmektedir. BIM farkındalık seviyesi Nijerya'da yüksektir fakat Güney Afrika 
sözleşme sorunları, personel eğitimi ve beceri geliştirme açısından yetersizlikler ve nüfus artış1, vb. gibi büyük sorunlarla karşı karşıyadır [12].

Türkiye'de BIM kullanımı ise diğer dünya ülkeleri baz alındığında henüz başlangıç aşamasında olarak değerlendirilebilir. Ancak bazı yerli firmaların uluslararası düzeydeki ihale edilen projelerinde ve sözleşmelerinde işveren talepleri doğrultusunda BIM kullanımına yönelim artmaya başlamıştır. Ancak Türkiye'deki çoğu firmanın alışkanlıklarından kopmak istememeleri, benimsemiş oldukları kendilerine özgü iş stratejilerinden vazgeçmek istememeleri, mevcut düzen ve metotlar içerisinde devam etmek istemeleri firmaların BIM'e geçiş süreçlerini ve adaptasyonunu etkileyen faktörlerdendir. Bir diğer önemli etken ise BIM kullanım oranlarının yüksek olduğu dünya ülkelerinde, BIM'e geçiş süreçlerinde referans alınabilecek kılavuzlar, el kitapları veya standartlar mevcut iken, Türkiye'de BIM'e geçiş süreçlerinde referans alınabilecek standartlar bulunmamaktadır. Bu sebepler ile BIM'e geçmeyi hedefleyen firmalar, ihtiyaçlarını belirlemede ve bu ihtiyaca cevap veren bir süreç yönetimi yapmakta zorlanmaktadırlar [13].

Özorhon ve Karahan (2016) tarafından yapılan çalışmada etkili BIM uygulamaları için temel başarı faktörleri belirlenmeye çalışılmıştır. BIM uygulamalarını olumlu veya olumsuz yönde etkileyen başarı faktörleri belirlenerek çalışma kapsamında bir anket çalışması yapılmıştır. Yapılan faktör analizi sonucunda toplam 16 adet temel başarı faktörü belirlenmiştir. En önemli faktörler (1) nitelikli personel, (2) etkin liderlik ve (3) bilgi ve teknoloji kullanımı olarak belirlenmiştir. BIM uygulamalarının etkin bir şekilde gerçekleşmesinde hem kamu sektörünün hem de özel sektörün önemli bir rolü olduğu vurgulanmıştır. Çalışmanın sonuçları Türkiye'de BIM kullanıcılarının genellikle BIM'i seviye 2 düzeyinde uyguladıklarını göstermektedir. BIM'in daha çok tasarım ve yapım öncesi aşamalarda kullanıldığı işletme ve bakım aşamasında kullanımının sınırlı olduğu ortaya çıkmıştır [14].

Öktem ve Ergen (2017) tarafından yapılan çalışmada Türk yapı sektöründe BIM kullanımına geçiş yapmak isteyen firmaların adaptasyon süreçlerinde zorluk yaşamamaları için kılavuz olarak kullanabilecekleri çerçevelerin oluşturulması amaçlanmıştır. Çalışma sonucunda organizasyonel ve operasyonel olmak üzere iki çerçeve geliştirilmiştir ve bu çalışma kapsamında yalnızca operasyonel çerçeve hakkında bilgi verilmiştir. Çalışmada BIM'e geçişin bir kültür değişimini beraberinde getirtiği ve adaptasyonun zaman alacağı vurgulanmış olup, bu çalışmada geliştirilen çerçeve yardımıyla adaptasyon sürelerinin kısaltılacağı ve BIM'in projeye olan faydalarının daha kısa sürede elde edileceği kanısına varılmıştır [13].

\section{Araştırma yöntemi}

BIM'in Türk yapı sektöründe adaptasyonunu incelemeyi amaçlayan bu çalışma için gerekli olan veriler bir anket çalışması yapılarak toplanmıştır. Çalışma kapsamında hazırlanan anket formuna "Yapı Sektöründe Yapı Bilgi Modellemesinin Adaptasyonu" adı verilmiştir.

\subsection{Anket formunun organizasyonu}

BIM'i henüz kullanmayan tasarım ve inşaat firmalarına yönelik düzenlenen anket formu 10 sorudan oluşmaktadır. Anket formu, 9 sorudan oluşmaktadır. Bu 9 sorunun; 5 tanesi 
kategorik ve 4 tanesi Likert tipidir. Anketin ilk sorusu; çalışanların firmadaki pozisyonunu belirlemeye yöneliktir. Anketin ikinci ve üçüncü soruları; firmaların kurumsal özelliklerini belirlemeyi amaçlamaktadır. Anketin dördüncü ve beşinci sorular1; yapı bilgi modellemesi konusunda firmaların ve katılımcıların deneyimlerini belirlemeye yönelik ifadelerden oluşmaktadır. Anketin son 4 sorusu Likert tipindedir. Katılımcılara yanıtlarını 5 noktalı Likert ölçeği üzerinde belirtmeleri istenmiştir. 5 noktalı Likert ölçeğinde ' $1=$ hiç katılmıyorum', '2=katılmıyorum', '3=kararsızım', '4=katılıyorum', '5=tamamen katılıyorum' olarak derecelendirilmiştir. 6. soru firmaları BIM kullanmaya engelleyen /engelleyecek faktörleri, 7.soru ise BIM kullanmaya motive edecek faktörleri belirlemeye yöneliktir. 7. soru hazırlanırken, Tulubas Gokuc ve Arditi (2017)'nin çalışmasındaki[2] anketin bazı ölçeklerinden yararlanılmıştır. 8.soru, mimarlık firmalarındaki üst yönetimin BIM adaptasyonu hususundaki eğilimlerini belirlemek amacı ile sorulmuştur. Son soru ise firma çalışanlarının BIM konusundaki yeterlilikleri belirlemek için oluşturulmuştur.

Çalışma serbest faaliyet gösteren, BIM'i henüz kullanmayan tasarım ve inşaat firmalarını kapsamaktadır. Hedef yanıtlayıcılar belirlendikten sonra, BIM'i henüz kullanmayan 536 firmanın Mimarlar ve İnşaat Mühendisleri Odası aracılığıyla e-posta adreslerine ulaşılmıştır. E-posta adresine ulaşılamayan bazı firmalarla da (firma sayısı 26) yüzyüze görüşmeler yolu ile temasa geçilmiştir. Anket soruları SurveyMonkey uygulamasında hazırlanmış ve bu uygulama vasıtasıyla katılımcılara e-posta ile gönderilmiştir. Toplamda anket çalışması 108 katılımcıdan (anketlerin geri dönüş oranı \%20) alınan bilgilerle değerlendirilmiştir.

\section{Araştırma bulguları}

Anket katılımcılarının \%67,59'u firmalarında mimar, \%25,00'i inşaat mühendisi, $\% 4,63$ 'ü genel müdür \%1,85'i proje müdürü, $\% 0,93$ 'ü ise dizayn ofis şefi, pozisyonunda çalışmaktadır (Şekil 1).

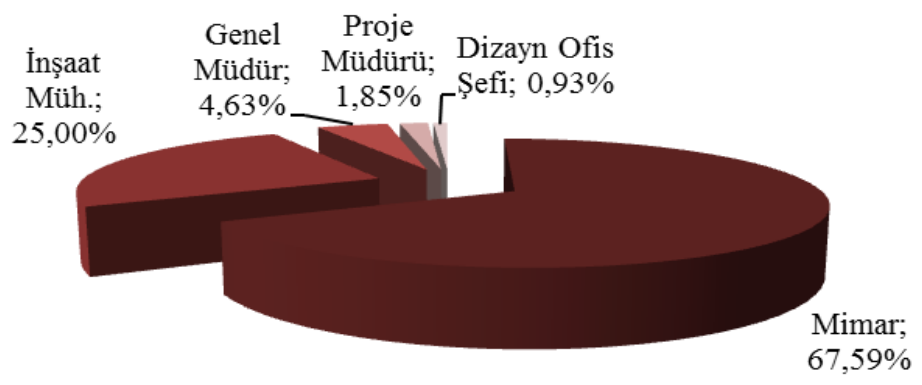

Şekil 1. Katılımcıların firmalardaki pozisyonları.

Şekil 2'de ise anket katılımcılarının sektördeki çalışma yıllarının dağılımı verilmiştir. $\mathrm{Bu}$ dağılıma göre katılımcıların \%33,33'ü sektörde 1 ile 3 yıl, \%35,19'u 4 ile 10 yıl, \%21,30'u 11 ile 20 yıl, \%7,41'i 21 ile 30 yıl arasında çalışırken, \%2,78'i 30 yılı aşkın süredir çalışmaktadır. 


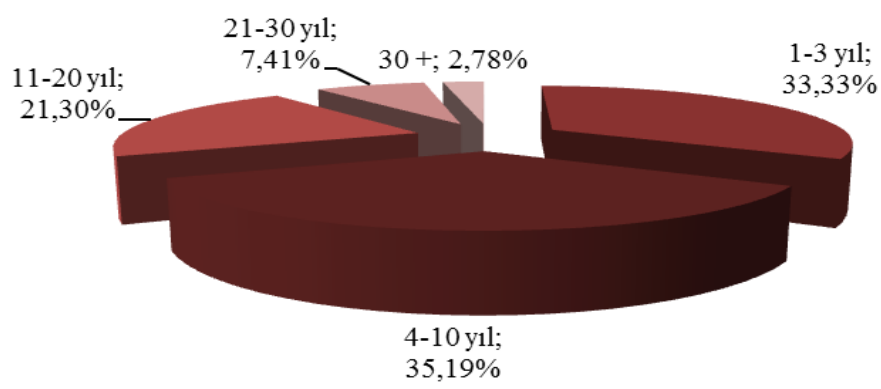

Şekil 2. Katılımcıların sektördeki çalışma yıllarının dağılımı.

Firmaların çalışan sayılarına göre dağılımı Şekil 3'de verilmiştir. Firmaların \%67,59'unda 1 ile 10 kişi, \%11,11'inde 11 ile 20 kişi, \%3,70'inde 21 ile 30 kişi, $\% 2,78$ 'inde 31 ile 50 kişi çalışmaktadır. Ankete katılan firmaların \%14,81'inde ise 50 kişiden fazla personel çalışmaktadır.

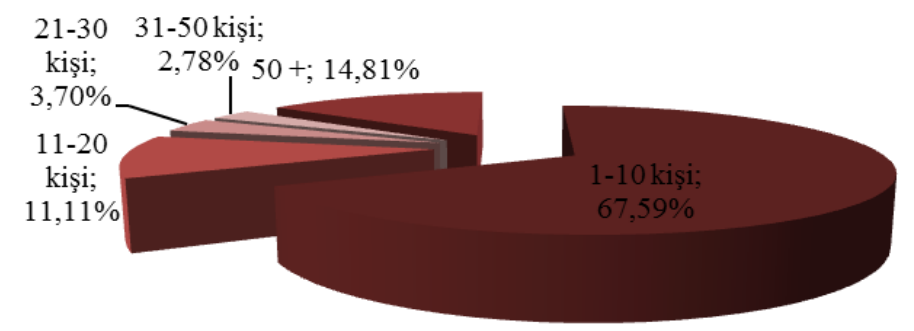

Şekil 3. Firmaların çalışan sayılarına göre dağılımı.

Şekil 4 firmaların kurumsal yaşlarının dağılımını göstermektedir. Firmaların \%26,85'i 0 ile 5 yıldır, \%25'i 6 ile 10 yıldır, \%15,74'ü 11 ile 15 yıldır, \%3,70'i 16 ile 20 yıldır ve $\% 28,70$ 'i de 20 yılı aşkın süredir sektörde faaliyet göstermektedir.

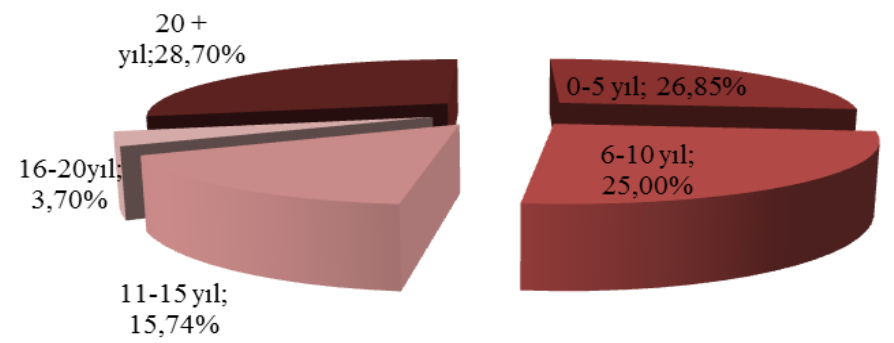

Şekil 4. Firmaların kurumsal yaşlarına göre dağılımı.

Şekil 5 katılımcıların BIM (Yapı Bilgi Modellemesi) konusundaki bilgi düzeylerini göstermektedir. Katılımcıların \% 22,22'si BIM hakkında hiçbir fikri olmadığını, $\% 37,04$ 'ü biraz, \%31,48'i orta seviyede, \%3,70'i iyi seviyede ve \%5,56's1 da çok iyi seviyede bilgi sahibi olduğunu düşünmektedir. 


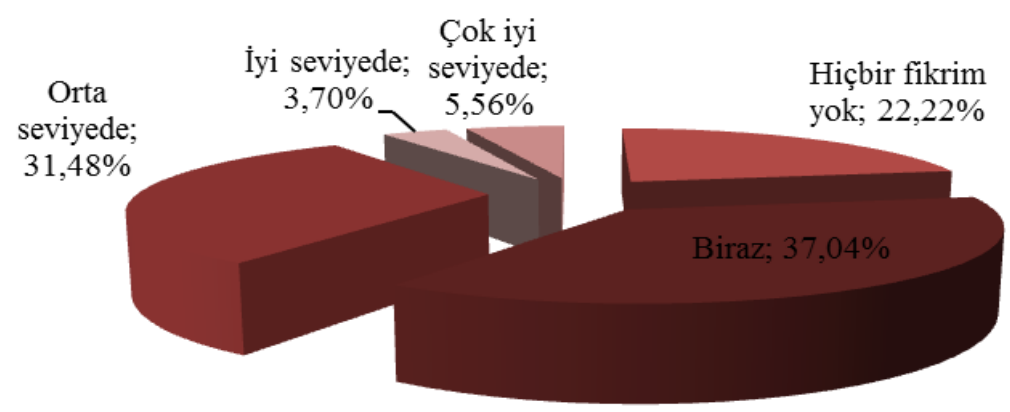

Şekil 5. Katılımcıların BIM konusundaki bilgi düzeyleri.

Şekil 6 mimarların ve mühendislerin BIM kullanımına engel olarak gördükleri faktörleri göstermektedir. Buna göre; sektördeki paydaşlar ve alt yüklenicilerin BIM konusunda yetersiz olması en önemli faktör olarak ortaya çıkmıştır (ortalama=4,23). Ayrıca BIM'in potansiyel faydalarının firmalar tarafından henüz anlaşılamamış olması (ortalama=4,22) ve BIM konusunda uzman işgücü eksikliği (ortalama=4,00) BIM adaptasyonunu engelleyen en önemli diğer iki faktördür.

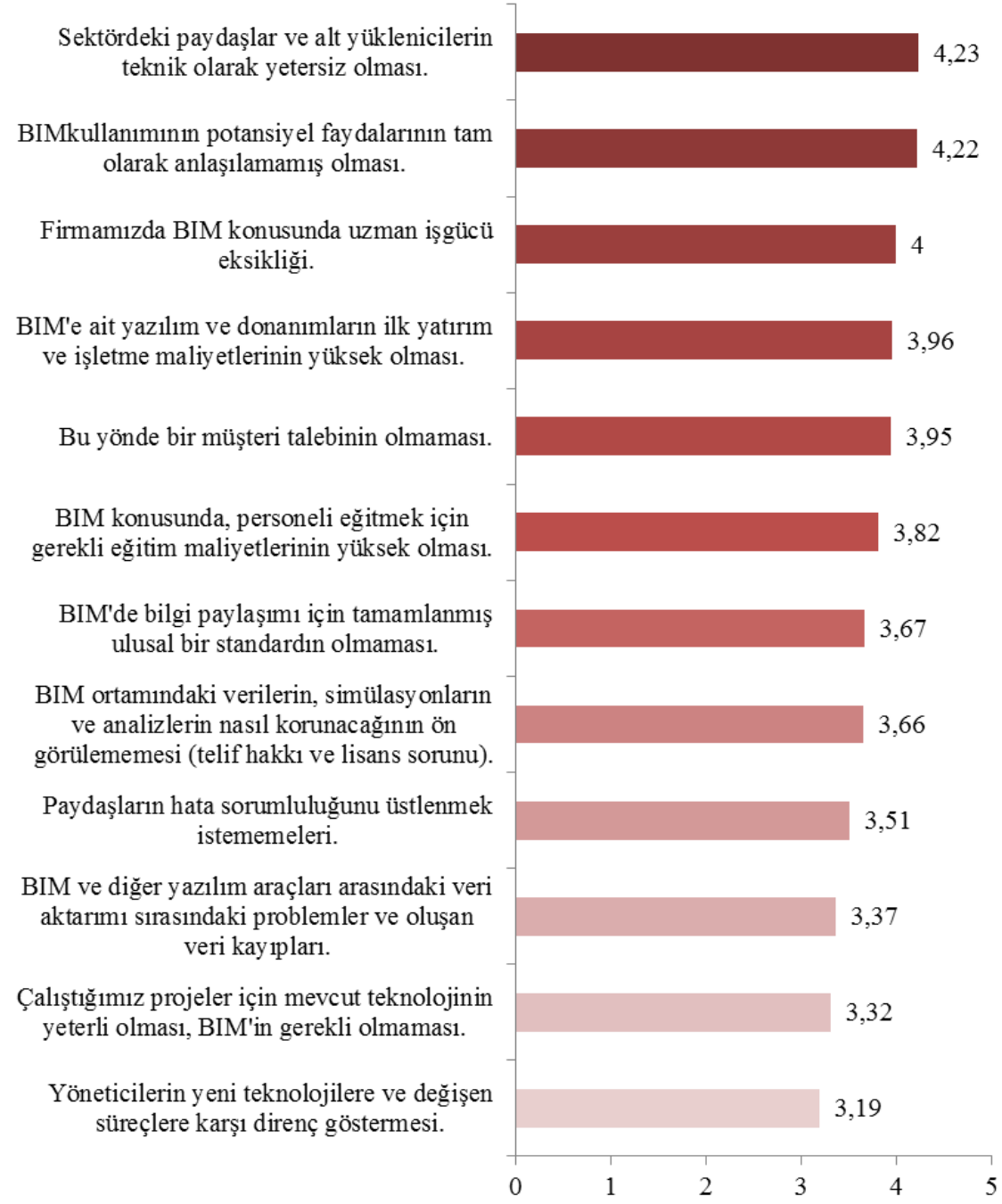

Şekil 6. BIM kullanımını engelleyen faktörler, ortalama değerler. 
Şekil 7 ise, firmaları BIM kullanımına yöneltecek faktörleri göstermektedir. Tasarım çözümlerinin daha iyi görselleştirilmesi $(\mathrm{Ort}=4,19)$ firmaları BIM kullanımına yönlendirecek en önemli faktördür. Görselleştirme birçok araştırmacı tarafından BIM'in en önemli faydası olarak görülür[15,16].

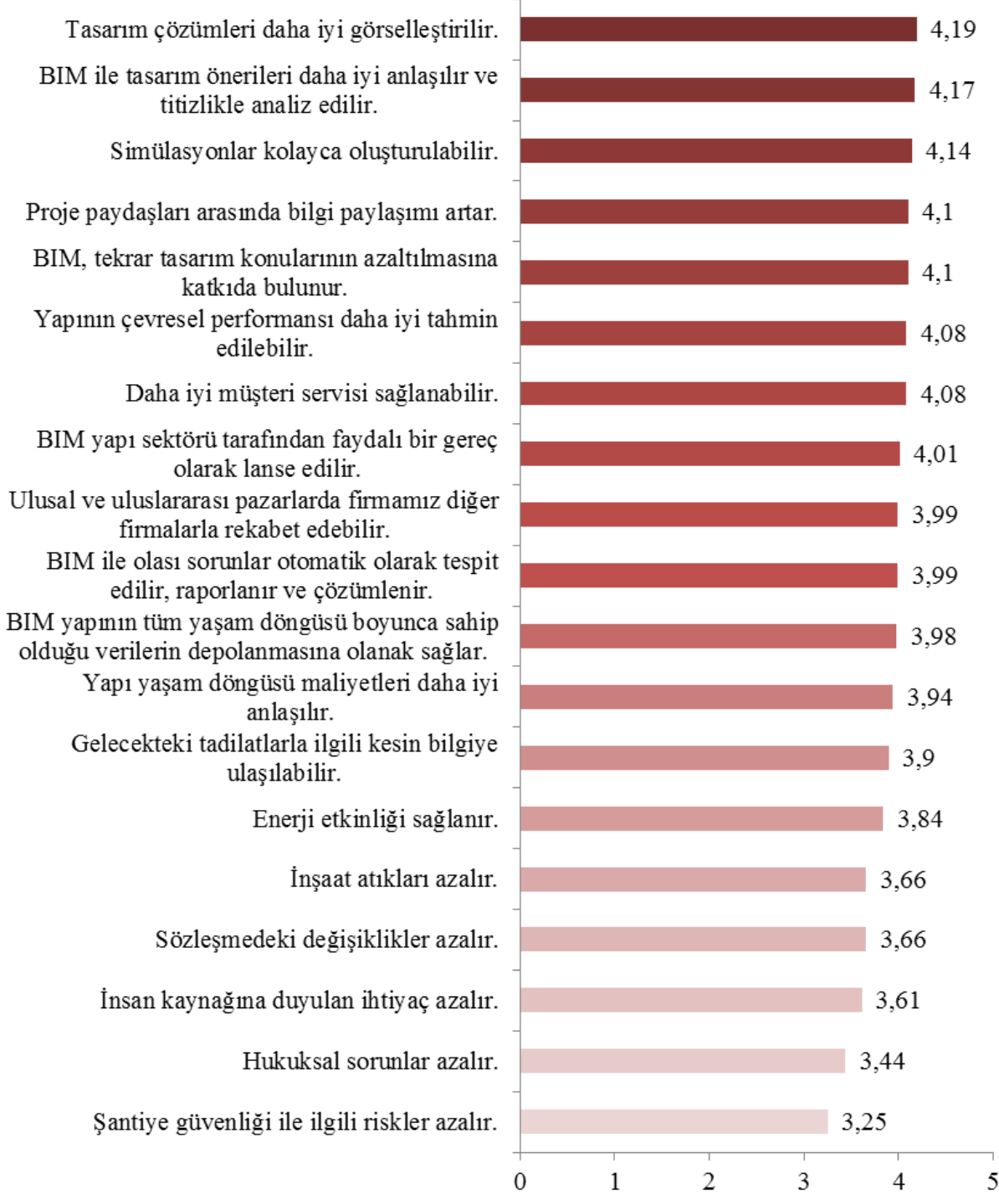

Şekil 7. Firmaları BIM kullanımına yöneltecek faktörler.

Şekil 8 ise firmalarda üst yönetimin desteği açısından durum tespitini göstermektedir. Sonuçlara bakıldığında; firmamız BIM'in potansiyel faydalarından habersizdir (ortalama $=3,61$ ) ve firmamızda BIM uygulaması için gerekli kaynaklar (yazılım ve donanım) sağlanır (ortalama $=3,19$ ) ifadeleri ön plana çıkmaktadır. Bir organizasyonun BIM'i adapte etme kararı üst yönetimin desteği olmadıkça risklidir. Bazı çalışmalarda üst yönetimin desteği BIM adaptasyonunda ana başarı faktörlerindendir[17]. 


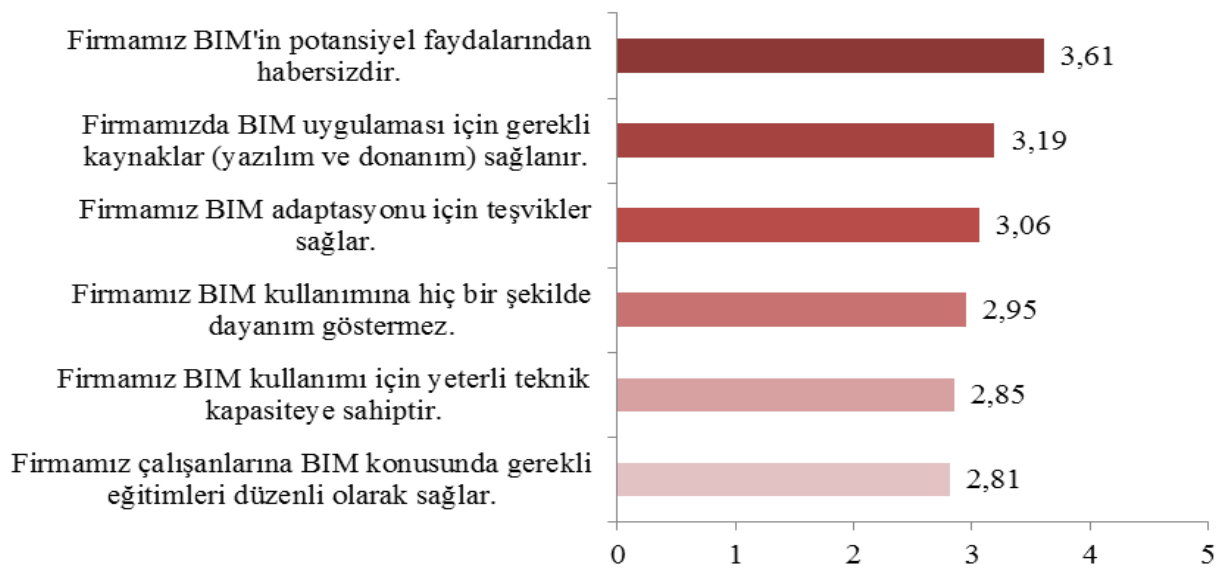

Şekil 8. BIM kullanımı ile ilgili üst yönetimin desteği.

Şekil 9 katılımcıların BIM konusundaki yeterliliklerini göstermektedir. Çalışanlar kendilerini BIM konusunda yeterli hissetmekle birlikte firmaların BIM ile ilgili eğitim desteğine ihtiyacı olduğu görülmektedir. Ayrıca anket katılımcılarının çoğunun lisans eğitimleri kapsamında müfredatlarında BIM ile ilgili derslerin olmadığg görülmektedir.

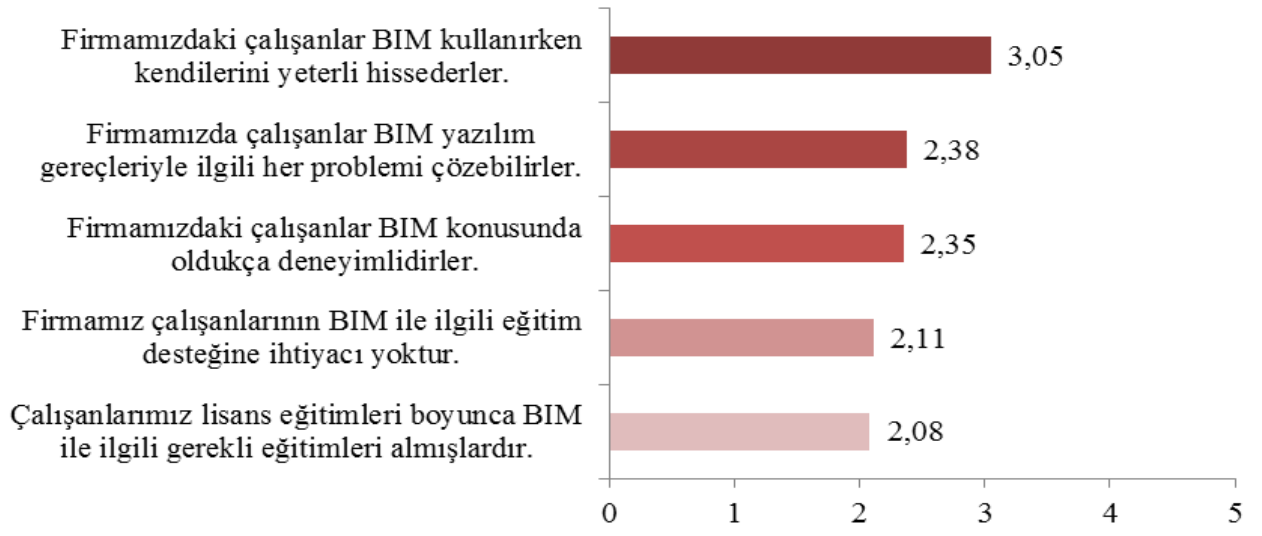

Şekil 9. Katılımcıların BIM konusundaki yeterlilikleri.

\section{Tartışma}

Çalışmanın sonuçlarına bakıldığında; Türk yapı sektöründeki firmaları BIM kullanımına engel teşkin eden faktörlerden en önemlisi sektördeki paydaşlar ve alt yüklenicilerin BIM konusunda yetersiz olmasıdır (ortalama=4,23). Ayrıca BIM'in potansiyel faydalarının firmalar tarafından henüz anlaşılamamış olması (ortalama=4,22) ve BIM konusunda uzman işgücü eksikliği (ortalama=4,00) BIM adaptasyonunu engelleyen en önemli diğer iki faktördür. Çalışmada firmaları BIM kullanımına yönlendirecek faktörlerden en önemlileri; tasarım çözümlerinin daha iyi görselleştirilmesi (ortalama=4,19), BIM ile tasarım önerilerinin daha iyi anlaşılması ve titizlikle analiz edilebilmesi (ortalama $=4,17)$ ve simülasyonların kolayca oluşturulabilmesidir (ortalama=4,14). 4,19 ortalama ile tasarım çözümlerinin daha iyi görselleştirilmesi firmaları BIM kullanımına yönlendirecek en önemli faktördür. Görselleştirme birçok araştırmacı tarafından BIM'in en önemli faydası olarak görülür [13,16,18]. Hergunsel (2011)'e göre [15]; BIM binanın 3 boyutlu sanal bir temsilini 
sağladığı için iyi bir görselleştirme aracıdır. Görselleştirme sonuç ürünün nasıl görüneceğinin daha iyi anlaşılmasına yardımcı olur.

Geliştirilmiş görselleştirme, bina önerilerinin doğru analizine yardımcı olur. İşveren ya da son kullanıcının geri bildirimlerine dayalı olarak farklı tasarım alternatifleri ve konfigürasyonları kolaylıkla modellenebilir ve gerçek zamanlı olarak değiştirilebilir. 3 boyutlu doğru bir görselleştirmenin kullanımı; farklı tasarım çözümlerini anlamak için fiziksel modellere duyulan ihtiyacı ortadan kaldırır [19]. BIM ile simülasyonlar kolayca oluşturulabilirler. BIM'in en önemli faydalarından biri, tasarımcıların farklı mevsimlerdeki güneş 1şığı gibi değişkenleri görselleştirmesini sağlayan veya bina enerji performansı hesabının yapılmasına imkan veren simülasyon araçlarıdır. Simülasyonlar; tasarımcılara tasarım, yapım ve bakım aşamalarının rafine olmasında yardımcı olurlar. Aynı zamanda karar alma süreçlerini geliştirdikleri için paydaşlara farklı alternatifler sunabilmek için önemlidirler. Issa ve diğerleri'nin (2009) çalışması da [20] önümüzdeki 10 yılda BIM kullanılarak yapılan simülasyonlarda artış olacağını öngörmektedir. Çalışma bulgularına üst yönetimin desteği açısından bakıldığında; "firmamız BIM'in potansiyel faydalarından habersizdir" (ortalama $=3,61$ ) ve "firmamizda BIM uygulamas1 için gerekli kaynaklar (yazılım ve donanım) sağlanır (ortalama=3,19)" ifadeleri ön plana çıkmıştır. Bir organizasyonun BIM'i adapte etme kararı üst yönetimin desteği olmadıkça risklidir. Gilligan ve Kunz (2007) ve Lee ve diğerleri'nin(2005) çalışmalarında üst yönetimin desteği BIM adaptasyonunda ana başarı faktörlerindendir [17;21]. McGraw-Hill yapım raporuna göre [6], BIM adaptasyonu 2007'de \%28 iken 2012'de \%70'e kadar çıkmıştır. BIM'in geleceğin trendi olduğu çok açıktır. Bew ve Underwood (2010) çalışmalarında [22]; BIM adaptasyonunun başarılı olabilmesinin değişimi kabul etmeye hazır bir organizasyon kültürü ile mümkün olacağını vurgulamışlardır.

Çalışanların BIM ile ilgili yeterlilikleri açısından sonuçlar değerlendirildiğinde; yanıtlayanların en çok "firmamızdaki çalışanlar kendilerini BIM konusunda yeterli hissederler (ortalama=3,05)" ve "çalışanlar BIM Yazılım gereçleriyle ilgili her problem çözebilirler (ortalama=2,38)" ifadelerine katıldıkları göze çarpmaktadır. Ayrıca anket katılımcılarının çoğunun lisans eğitimleri kapsamında müfredatlarında BIM ile ilgili derslerin olmadığ görülmektedir. Sadece ülkemizde değil BIM adaptasyonu konusunda önde giden ülkelerden biri olan Amerika'da da durumun çok farklı olmadığı görülmektedir [23]. Ders müfredatlarında BIM'in yer almaması BIM ile ilgili dersleri öğretecek uzmanların olmamasından kaynaklanmaktadır. Üniversitelerde BIM öğrenimi gelecekteki profesyonelleri pratiğe hazırlamak için faydalı olabilir [24]. Firma çalışanlarının BIM konusunda eğitim desteğine ihtiyacı olduğu açıktır. Anket katılımcılarının çoğu firmalarının BIM'in potansiyel faydalarından habersiz olduğu görüşündedir. Firmalar BIM için yeterli teknik kapasiteye sahip değildir ve çalışanlarına BIM konusunda gerekli eğitimleri düzenli olarak sağlamamaktadırlar.

\section{Sonuç}

Yap1 sektöründe faaliyet gösteren firmaların ulusal ve uluslararası pazarlarda rekabet edebilmeleri için; zaman ve maliyet kayıplarını en aza indirmeleri, sürdürebilir projeler üretebilmeleri, enerji ve kaynakları daha etkin ve verimli kullanılabilmeleri ve proje sürecindeki tüm paydaşlar arasında etkili işbirliği ve bilgi paylaşımı sağlayabilmeleri gerekmektedir. Projenin sadece ön yapım ve yapım aşamasını değil yapım sonrası 
aşamaları da kapsayan bilgilerin en doğru şekilde depolanıp yönetilmesi bu nedenle oldukça önemlidir. BIM'in, firmaların beklentilerini tam olarak karşılayabilmesi BIM uygulamalarının etkin bir şekilde kullanımı ile mümkündür.

Pek çok ülkede zorunlu olan BIM'in kullanımı Türkiyede de zamanla artmaktadır. İlk olarak, havalimanları, raylı sistem ve hastane projelerinde kullanılan BIM'in kısa sürede ülkemizde yapı sektörünün önemli bir parçası olacağı düşünülmektedir. $\mathrm{Bu}$ nedenle BIM'in potansiyel faydalarının farkında olan firmaların sistemi kullanabilmesi için işverenlerin (kamu ve özel sektör) projelerde BIM kullanımı zorunlu kılarak destek sağlaması önemlidir. Bu çalışmanın sonuçlarına göre; BIM'in adaptasyon sürecini önemli ölçüde etkileyen faktör, sektördeki paydaşların ve alt yüklenicilerin yetersizliğidir. BIM farkındalığını öncelikli olarak proje sürecinin önemli bir parçası olan sektördeki paydaşlara ve yüklenicilere aşılamak gerekmektedir. Dolasıyla hem üniversiteler hem de kamu ve özel sektör kurumlarına önemli roller düşmektedir.

Üniversitelerin lisans ve yüksek lisans programlarında yap1 sektöründe BIM'in potansiyel faydalarının farkındalığının artmasını sağlamak ve kullanımını teşvik etmek amacıyla müfredatlarında BIM ile ilgili derslere yer verilmesi sektöre BIM hakkında bilgi sahibi bireylerin yetişmesine katkı sağlayabilir. Ayrıca üniversitelerin, eğitim kurumların ve bazı kurum ve kuruluşların eğitim, seminer, konferans düzenlemesi BIM eğitimi için gereken maliyeti de minimuma indirebilir.

BIM'in kullanımının önüne geçen en büyük sorunlardan biri de ulusal bir standardın olmayışıdır. Bu nedenle BIM'in Türk yapı sektöründe kullanımının yaygınlaşmasını hızlandırmak için tüm ilgili kurum ve kişiler aracılığıyla ulusal BIM standartları, kılavuzları, kanun ve yönetmelikleri hazırlanıp kullanımını zorunlu kılan uygulamalarla teşvik edilmesi sağlanmalıdır. Yöneticilerin ise yeni teknolojilere ve değişen süreçlere direnç göstermemesi uyum sağlaması ve uzun vadeli geri dönüşler için sabırlı olması gereklidir. BIM kullanımının yaygınlaşması için yazılım ve donanımların ilk yatırım ve işletme maliyetleri ile eğitim maliyetleri en aza indirilmelidir. Bununla birlikte BIM ortamındaki verilerin, simülasyonların ve analizlerin nasıl korunacağının ön görülememesi de diğer bir engeldir.

\section{Kaynaklar}

[1] Yan, H. and Damian, P., Benefits and barriers of building information modeling, 12th International Conference on Computing in Civil and Building Engineering, Beijing, 1-6, (2008).

[2] Tulubas Gokuc Y. and Arditi D., Adoption of BIM in architectural design firms, Architectural Science Review, 60(6). 483-492, (2017).

[3] İnan, N., Yıldırım, T., Mimari tasarım sürecinde disiplinlerarası ilişkiler ve eşzamanl1-dijital ortam tasarım olanakları, Journal of the Faculty of Engineering and Architecture of Gazi University, 24(4), 583-595, (2009).

[4] Eastman, C., Teicholz, P., Sacks, R., Liston, K., BIM handbook: A guide to building information modeling for owners, managers, designers, engineers, and contractors, 2nd Ed., John Wiley \& Sons, Hoboken, 1-640, (2011).

[5] NIBS, United States National Building Information Modeling Standard Version 1 - Part 1: Overview, Principles, and Methodologies, (2007). 
[6] McGraw-Hill Construction Report, The business value of BIM in North America, SmartMarket Report, Bedford, MA: McGraw-Hill Construction, (2012).

[7] Bernstein, H. M., Jones, S. A., Russo, M. A., The business value of BIM in North America: Multi-year trend analysis and user rating (2007-2012), McGraw-Hill Construction, Bedford, MA,1-72, (2012).

[8] McGraw-Hill Construction Report, The business value of BIM in Europe, Getting building information modeling to the bottom line in the United Kingdom, France and Germany, SmartMarket Report, Bedford, MA: McGrawHill Construction, 1-52, (2010).

[9] Özorhon, B., Yapı bilgi modellemesi, İB İstanbul Anadolu Yakası Raylı Sistem Projeleri, Abaküs Yayıncılık, 1-152, (2018).

[10] Kekana, T.G., Aigbavboa C.O., Thwala W.D., Building information modelling (BIM) barriers in adoption and implementation strategies in the South Africa construction industry, International Conference on Emerging Trends in Computer and Image Processing, 15-16, (2014).

[11] Chan, C., Barriers of implementing BIM in construction industry from the designers perspective A Hong Kong, Journal of System and Management Sciences, 4, 24-40, (2018).

[12] Ogwueleka, A.C., Upgrading from the use of 2D CAD systems to BIM technologies in the construction industry consequences and merits, International Journal of Engineering Trends and Technology (IJETT), 28, 403-411, (2014).

[13] Öktem S.,Ergen E., BIM'e geçiş sürecinin operasyonel çerçevesi, 4. Uluslararas1 Katılımlı 7. İnşaat Yönetimi Kongresi, Samsun, Türkiye,627-635, (2014).

[14] Özorhon, B., Karahan, U., Critical success factors of building information modeling (BIM) implementation, ASCE Journal of Management in Engineering, 33 (3), 256-263, (2016).

[15] Hergunsel, M., Benefits of building information modeling for construction managers and Bim based scheduling. Thesis Submitted to the Faculty of Worcester Polytechnic Institute, 1-89, (2011).

[16] Qian, A. Y., Benefits and ROI of BIM for Multi-Disciplinary Project Management, National University of Singapore, 2012. Accessed March 03, 2019. http://www.icoste.org/wp-content/uploads/2011/08/Benefits-and-ROIofBIM-for-Multi-Disciplinary-Project-Management.pdf

[17] Gilligan, B. ,Kunz, J., VDC use in 2007: significant value, dramatic growth, and apparent business opportunity. CIFE Technical Rep. No. TR171, Stanford Univ., Palo Alto, CA, 1-40, (2007).

[18] Azhar, S., M. Hein, B. Sketo, Building information modeling: benefits, risks and challenges, Proceedings of the 44th ASC National conference, Auburn, AL, April 2-5,1-7, (2008).

[19] Sanchez, A. X., Hampson, K. D., Vaux, S., Delivering value with BIM: A whole-of-life approach, Abingdon: Routledge, 1-366, (2016).

[20] Issa, R. R., Suermann, P., Olbina S., Use of building information models in simulations, Proceedings of the 2009 winter simulation conference (WSC 09), Austin, TX, 2264-2271, (2009).

[21] Lee, S., Yu, J., Jeong D., BIM acceptance model in construction organizations, Journal of Management Engineering, 31(3), 1-113, (2015).

[22] Bew, M., Underwood, J., Delivering BIM to the UK market, In handbook of research on building information modelling and construction informatics: 
concepts and technologies, edited by Jason Underwood and Umit Isikdag, Hershey, New York: Information Science Reference, 30-64, (2010).

[23] Becerik-Gerber, B., Gerber, D., Ku K., The pace of technological innovation in architecture, engineering and construction education: integrating recent trends into the curricula, Journal of Information Technology in Construction, 16, 411-432, (2011).

[24] Becerik-Gerber, B., Kensek, K. Building information modeling in architecture, engineering and construction: emerging research directions and trends. ASCE Journal of Professional Issues in Engineering Education and Practice, 136 (3), 139-147, (2010). 